\title{
EULERIAN-EULERIAN SIMULATIONS OF THE HYDRODYNAMICS OF A BINARY MIXTURE IN AN INTERNALLY CIRCULATING FLUIDIZED BED
}

\author{
M. Hassan ${ }^{1}$, H. Lu ${ }^{2 *}$, G. Liu ${ }^{2}$, S. Wang ${ }^{2}$ and M. Rafique ${ }^{2}$ \\ ${ }^{1}$ U.S.-Pakistan Center for Advanced Studies in Energy, UET Peshawar, Pakistan. \\ ${ }^{2}$ School of Energy Science \& Engineering, Harbin Institute of Technology, Harbin, 150001, China.
}

(Submitted: February 12, 2017 ; Revised: April 30, 2017 ; Accepted: June 12, 2017)

\begin{abstract}
The process of solid circulation in an internally circulating fluidized bed (ICFB) having two or more chambers can be developed by applying unequal gas velocities in these chambers. Such a process is beneficial to several applications and provides the means for the energy transfer between the chambers in the ICFB. In this paper, a multi-fluid CFD model incorporating the kinetic theory of granular flow is used to simulate the hydrodynamic characteristics of a binary mixture of particles in an ICFB using ANSYS-Fluent software. The mixture is composed of two particles of different sizes but the same densities. The ICFB has two chambers named the reaction chamber (RC) and the heat exchange chamber (HEC), separated by a vertical central baffle. An increase in the $R C$ gas velocity $U_{R}$ at constant $\mathrm{HEC}$ gas velocity $\mathrm{U}_{\mathrm{H}}$ results in an increase in the circulation rate of the binary mixture. The circulation rate of small particles $\mathrm{GB}_{\mathrm{s}}$ is found to be higher than that of the big particles $\mathrm{GB}_{b}$. Increasing the slot size causes a decrease in the pressure difference between the chambers and consequently decreasing the solid circulation rate in the ICFB. The mixture circulation rate also decreases when the mixture is richer in $\mathrm{GB}_{\mathrm{b}}$ particles than in $\mathrm{GB}_{\mathrm{s}}$.

Keywords: Simulations; Kinetic theory of granular flow; CFD; Solid circulation rate; Pressure difference.
\end{abstract}

\section{INTRODUCTION}

Fluidized bed reactors in their various forms are very popular and commonly used in many industries throughout the world. The process of particle circulation in a fluidized bed is useful to many applications and it can either be achieved externally, such as in the conventional circulating fluidized bed (CFB), or internally, such as in the non-conventional internally circulating fluidized bed (ICFB). In CFBs, a cyclone collects the particles from the riser and returns them to the base of the riser. In contrast, ICFBs consist of a single vessel which is appropriately divided into two or more chambers by placing a plate (baffle) or a draft tube. Thus, the circulation of particles is developed in a single vessel just by applying different fluidization velocities in these chambers and the need for an extra component, i.e., a cyclone is eliminated. The ICFB chambers are termed the reaction chamber (RC) or fast bed and the heat exchange chamber (HEC) or slow bed. Due to their unique structure, ICFBs possess several advantages over CFBs such as reduced height, compact size, low construction cost and comparatively lower heat loss. Because of these advantages, ICFBs serve many purposes such as in coal combustion and gasification (Kim et al., 1997, Lee et al., 1998), biomass gasification (Xiao et al., 2010), disposal of solid waste (Mukadi et al., 1999a, Mukadi et al., 1999b, Milne et al., 1999), flue gas desulfurization (Chu and Hwang, 2005) and membrane reactors (Boyd et al., 2005). In

\footnotetext{
* Corresponding author Tel.: +0451 8641 2258, E-mail address: huilin@hit.edu.cn
} 
the case of coal/biomass gasification, the fast bed serves as combustor and the slow chamber as a gasifier; thus, energy is provided from the combustion chamber to the gasification chamber by the continuous internal solid circulation process. The solid circulation rate controls the solid residence time, gas-solid contact, and heat and mass transfer rates in the bed. Therefore, it needs to be determined carefully to provide the prerequisite information to design an ICFB reactor (Jeon and Kim, 2010). The experiments (Kim et al., 2002) have shown that solid recirculation increased upon increasing the superficial gas velocity, but decreased upon increasing the particle diameter. It was found (Luo et al., 2013) that the particle diameter has a great impact on the ICFB performance and an increase in the particle size results in a decrease of the solid circulation rate. As compared to a conventional fluidized bed, an efficient energetic exchange between the sand and biomass particles can be obtained in an ICFB due to its ability of internal recirculation (Foscolo et al., 2007). This will result in good mixing and will reduce the segregation of biomass particles to the bed surface, along with the reduction in the elutriation of fine carbon particles, ultimately improving the yield and quality of the product gas. Similarly, the fluidization of wide size distribution (WSD) particles in an ICFB was found to be better than the conventional fluidized bed along with a considerable minimization in the segregation of the WSD particles due to continuous solid recirculation (Li et al., 2015).

Obtaining complete knowledge of the complex gas solid dynamics in an industrial ICFB by experiments is a tough task even for a cold state process, and it becomes even more challenging in situations when chemical reactions or high temperatures are also present. To overcome such challenges, given the tremendous improvement in computing power, it has been shown that computer modeling can complement experiments as a beneficial tool to elaborate complex multiphase gas-solid hydrodynamics such as those encountered in ICFBs. The effect of different design and operating parameters on the bed performance in a two dimensional ICFB has been evaluated by CFD simulations using a two-fluid model incorporating the kinetic theory of granular flow (KTGF) (Feng et al., 2012, Hassan et al., 2016, Hassan et al., 2017). The results showed that the solid circulation between two chambers in the ICFB is influenced by the superficial fluidizing velocities of RC and HEC, static bed height, gas distributor design and structure of the ICFB.

Fluidized bed systems usually operate with complex bed materials of different properties, size and density such as mixtures of sand, coal, biomass, sorbents and bottom ash etc. Many studies have been carried out to investigate the behavior of the binary mixtures of particles in bubbling and circulating fluidized beds (Goldschmidt et al., 2001, Huilin and Gidaspow,
2003, Huilin et al., 2003, Gera et al., 2004, van Sint Annaland et al., 2009, Bai et al., 2013, Zhong et al., 2012). However, the hydrodynamic characteristics of binary mixtures in an ICFB have rarely been reported in the literature. Therefore, it is necessary to study the flow behavior of such a system.

The objective of the present work is to simulate a baffle type internally circulating fluidized bed containing a binary mixture of particles having the same densities but different sizes, using a multi-fluid Eulerian model. The influence of design and operating parameters such as superficial gas velocities, variation in concentration of the constituent particles and slot size is investigated and the results are quantified in terms of solid circulation rate $\left(\mathrm{G}_{\mathrm{s}}\right)$.

\section{CFD MODEL DESCRIPTION}

A summary of the governing equations, along with the associated constitutive sub-models of the EulerianEulerian model incorporating the kinetic theory of granular flow (Schaeffer, 1987, Gidaspow, 1994) used in the simulation of the internally circulating fluidized bed, is presented in this section.

The continuity equation for the gas phase can be written as:

$$
\frac{\partial}{\partial t}\left(\alpha_{a} \rho_{a}\right)+\nabla \cdot\left(\alpha_{a} \rho_{a} u_{a}\right)=0
$$

For a system having $\mathrm{n}$ solid phases, the continuity equation for each solid phase $i(i=1, \ldots, \mathrm{n})$ without any mass transfer is written as:

$$
\begin{aligned}
& \frac{\partial}{\partial t}\left(\alpha_{i} \rho_{i}\right)+\nabla \cdot\left(\alpha_{i} \rho_{i} u_{i}\right)=0 \\
& \alpha_{a}+\sum_{i=1}^{n} \alpha_{i}=1
\end{aligned}
$$

where $n=2$ here.

The momentum conservation equations for the gas and solid phases are:

$$
\begin{aligned}
& \frac{\partial}{\partial t}\left(\alpha_{a} \rho_{a} u_{a}\right)+\nabla \cdot\left(\alpha_{a} \rho_{a} u_{a} u_{a}\right)= \\
& -\alpha_{a} \nabla p+\nabla \cdot \overline{\bar{\tau}}_{a}+\alpha_{a} \rho_{a} g+\sum_{i=1}^{n} \beta_{a i}\left(u_{i}-u_{a}\right) \\
& \frac{\partial}{\partial t}\left(\alpha_{i} \rho_{i} u_{i}\right)+\nabla \cdot\left(\alpha_{i} \rho_{i} u_{i} u_{i}\right)= \\
& -\alpha_{i} \nabla p+\nabla \cdot \overline{\bar{\tau}}_{i}-\nabla P_{i}+\alpha_{i} \rho_{i} g-\beta_{a i}\left(u_{i}-u_{a}\right)+\sum_{i=1, i \neq j}^{n} \beta_{i j}\left(u_{i}-u_{j}\right)
\end{aligned}
$$


The conservation equation for the fluctuation energy of the solid particles (granular temperature) is written as:

$$
\begin{aligned}
& \frac{3}{2}\left[\frac{\partial}{\partial t}\left(\alpha_{i} \rho_{i} \Theta_{i}\right)+\nabla \cdot\left(\alpha_{i} \rho_{i} u_{i} \Theta_{i}\right)\right]= \\
& \left(-p_{i} \overline{\bar{I}}+\overline{\bar{\tau}}_{i}\right): \nabla u_{i}+\nabla \cdot\left(k_{\Theta_{i}} \nabla \Theta_{i}\right)-\gamma_{\Theta_{i}}-3 \beta_{a i} \Theta_{i}
\end{aligned}
$$

The constitutive equations used for the E-E model are (Lun et al., 1984, Gidaspow et al., 1991, Syamlal et al., 1993):

Gas phase stress tensor:

$$
\overline{\bar{\tau}}_{a}=\alpha_{a} \mu_{a}\left[\nabla u_{a}+\left(\nabla u_{a}\right)^{T}\right]-\frac{2}{3} \alpha_{a} \mu_{a} \nabla \cdot u_{a} \overline{\bar{I}}
$$

Solid phase stress tensor:

$$
\overline{\bar{\tau}}_{i}=\alpha_{i} \mu_{i}\left[\nabla u_{i}+\left(\nabla u_{i}\right)^{T}\right]+\alpha_{i}\left(\lambda_{i}-\frac{2}{3} \mu_{i}\right)\left(\nabla \cdot u_{i}\right) \overline{\bar{I}}
$$

Solid shear viscosity:

$$
\mu_{i}=\mu_{i, \text { collision }}+\mu_{i, \text { kinetic }}+\mu_{i, \text { frictional }}
$$

where

$$
\begin{aligned}
& \mu_{i, \text { collision }}=\frac{4}{5} \alpha_{i} \rho_{i} d_{i} g_{i j}\left(1+e_{i j}\right) \sqrt{\frac{\Theta_{i}}{\pi}} \\
& \mu_{i, \text { kinetic }}=\frac{10 \rho_{i} d_{i} \sqrt{\Theta_{i} \pi}}{96 \alpha_{i} g_{i j}\left(1+e_{i j}\right)}\left[1+\frac{4}{5} \alpha_{i} g_{i j}\left(1+e_{i j}\right)\right]^{2} \\
& \mu_{i, \text { frictional }}=\frac{P_{i} \sin \theta_{i}}{2 \sqrt{I_{2 D}}}
\end{aligned}
$$

Solid bulk viscosity:

$$
\lambda_{i}=\frac{4}{3} \alpha_{i} \rho_{i} d_{i} g_{i j}\left(1+e_{i j}\right) \sqrt{\frac{\Theta_{i}}{\pi}}
$$

Collision energy dissipation:

$$
\gamma_{\Theta_{i}}=\frac{12\left(1+e_{i j}^{2}\right) g_{i j}}{d_{i} \sqrt{\pi}} \rho_{i} \alpha_{i}^{2} \sqrt{\Theta_{i}^{3}}
$$

Solid pressure:

$$
P_{i}=\alpha_{i} \rho_{i} \Theta_{i}\left[1+2 \sum_{i=1}^{2}\left(\frac{d_{i}+d_{j}}{2 d_{i}}\right)\left(1+e_{i j}\right) a_{j} g_{i j}\right]
$$

Radial distribution function:

$$
g_{i}=\left[1-\sqrt[3]{\frac{\alpha_{s}}{\alpha_{s, \max }}}\right]^{-1}+\frac{1}{2} d_{i} \sum_{i=1}^{2} \frac{\alpha_{i}}{d i}, g_{i j}=\frac{d_{i} g_{j}+d_{j} g_{i}}{d_{i}+d_{j}}
$$

where $\alpha_{\mathrm{s}}$ is the total solid volume fraction and $\alpha_{\mathrm{s}, \max }$ is the maximum packing limit. It can be calculated for a binary mixture according to the empirical method of Fedors and Landel (Fedors and Landel, 1979) and is well documented by ANSYS-Fluent (Fluent, 2012).

Diffusivity of granular temperature:

$$
\begin{aligned}
k_{\Theta_{i}} & =\frac{150 \rho_{i} d_{i} \sqrt{\Theta_{i} \pi}}{384\left(1+e_{i j}\right) g_{i j}}\left[1+\frac{6}{5} \alpha_{i} g_{i j}\left(1+e_{i j}\right)\right]^{2}+ \\
& +2 \alpha_{i}^{3} \rho_{i} d_{i} g_{i j}\left(1+e_{i j}\right) \sqrt{\frac{\Theta_{i}}{\pi}}
\end{aligned}
$$

Solid-solid exchange coefficient:

$$
\beta_{i j}=\frac{3\left(1+e_{i j}\right)\left(\frac{\pi}{2}+C_{f r, i j} \frac{\pi^{2}}{8}\right) \alpha_{i} \rho_{i} \alpha_{j} \rho_{j}\left(d_{i}+d_{j}\right)^{2} g_{i j}}{2 \pi\left(\rho_{i} d_{i}^{3}+\rho_{j} d_{j}^{3}\right)}\left|u_{i}-u_{j}\right|
$$

\section{Gas-solid Drag Coefficient}

Several gas-solid drag coefficient $\left(\beta_{a i}\right)$ correlations are available, among which the Gidaspow drag model (recommended for a dense fluidized bed) and the Syamlal-O'Brien model are the most commonly used in the literature. Various studies have been carried out to investigate the effect of different drag models on the flow behavior in bubbling or circulating fluidized beds (Taghipour et al., 2005, Loha et al., 2012), but no such research is available for an ICFB. The following model of Gidaspow for the inter-phase momentum exchange coefficient for the drag between the gas and solid phases has been applied in this paper.

$$
\begin{aligned}
& \beta_{a i}=\frac{3}{4} C_{D} \frac{\alpha_{i} \alpha_{a} \rho_{a}\left|u_{a}-u_{i}\right|}{d_{i}} \alpha_{a}^{-2.65} \text { for } \alpha_{a} \geq 0.8 \\
& \beta_{a i}=150 \frac{\alpha_{i}\left(1-\alpha_{a}\right) \mu_{a}}{\alpha_{a} d_{i}^{2}}+1.75 \frac{\alpha_{s} \rho_{a}\left|u_{a}-u_{i}\right|}{d_{i}} \text { for } \alpha_{a}<0.8
\end{aligned}
$$

where

$C_{D}= \begin{cases}\frac{24}{\operatorname{Re}_{i}}\left[1+0.15\left(\mathrm{Re}_{i}\right)^{0.687}\right] & \text { for } \quad \mathrm{Re}_{i} \leq 1000 \\ 0.44 & \text { for } \quad \mathrm{Re}_{i}>1000\end{cases}$

$$
\operatorname{Re}_{i}=\frac{\alpha_{a} \rho_{a}\left|u_{a}-u_{i}\right| d_{i}}{\mu_{a}}
$$


The solid circulation rate $\left(G_{s}\right)$ is calculated from the simulated solid velocity and voidage at the slot below the baffle (Fang et al., 2013, Hassan et al., 2016). The same method is applied for calculating the gas bypassing rate $\left(\mathrm{G}_{a}\right)$.

$$
\begin{aligned}
& G_{s}=\frac{1}{A} \int \rho_{s}\left(1-\alpha_{a}\right) u_{s} d A \\
& G_{s}=\frac{1}{A} \int \rho_{a} \alpha_{a} u_{a} d A
\end{aligned}
$$

\section{SIMULATION SETUP AND BOUNDARY CONDITIONS}

The geometry of the simulated ICFB shown in Figure 1 has a height (y), width (x) and depth (z) of $0.70,0.305$ and $0.02 \mathrm{~m}$, respectively. The ICFB consists of two inter-connected fluidized bed chambers named the reaction chamber (RC) and heat exchange chamber (HEC), separated by a vertical baffle. For the base cases (cases other than the slot size variation), the length and width of the central baffle are 130 and $5 \mathrm{~mm}$, respectively, creating a $20 \mathrm{~mm}$ slot beneath it. The gap or slot under the baffle serves as a means for the solids to return from the HEC to the RC. Simulation parameters are listed in Table 1. The mixture consists of two types of glass bead particles termed $\mathrm{GB}_{\mathrm{b}}$ (big particles) and GB (small particles) having the same density but different size. An initial solid volume fraction of 0.6 ( $50 \%$ for each granular phase) corresponding to a static bed height equal to that of the baffle height is defined throughout the simulations.

Table 2 describes the simulation strategy, where $\mathrm{U}_{\mathrm{R}}$ and $\mathrm{U}_{\mathrm{H}}$ are the superficial gas velocities in $\mathrm{RC}$ and HEC and $x_{b}$ and $x_{s}$ represents the concentration of the big $\left(\mathrm{GB}_{\mathrm{b}}\right)$ and small $\left(\mathrm{GB}_{\mathrm{s}}\right)$ particles in the mixture. The velocity inlet condition is specified for the gas phase with no solid flow at the inlet while the outlet of the reactor is at atmospheric pressure. In multiphase flow, wall boundary conditions for the solid phase can be defined in several ways such as no slip, free slip and

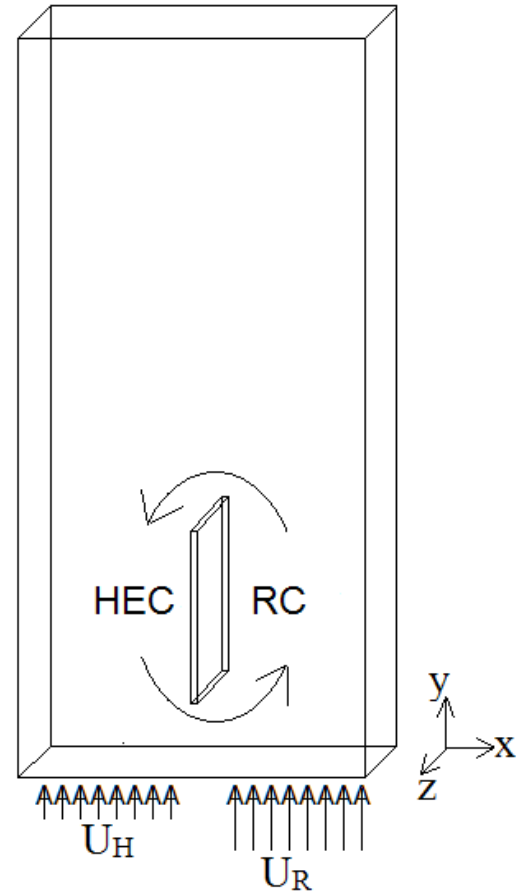

Figure 1. Layout of the ICFB.

partial slip. In our simulations, we apply the no slip boundary condition for the gas phase at the walls, while the Johnson and Jackson (1987) slip wall boundary condition is used for each granular phase. The particleparticle coefficient of restitution is set equal to 0.97 . The model equations are solved by using the commercial CFD software ANSYS-Fluent (Manual, 2012). The pressure based second order implicit unsteady solver is selected. Phase Coupled SIMPLE algorithm is used for the pressure-velocity coupling, along with the high order discretization scheme QUICK to ensure the accuracy of the simulations. The uniform grid size of $0.5 \mathrm{~cm}$ is employed in all directions with a time step of $0.001 \mathrm{~s}$, since such a criterion was successfully applied in the previous study (Goldschmidt et al., 2001) of binary mixtures of this nature to get reasonably accurate results.

Grid sensitivity analysis is a crucial step in carrying out numerical simulations. To make sure that the present

\begin{tabular}{|c|c|c|c|}
\hline Solid properties & Unit & - & - \\
\hline Particle type & - & Big particles & Small particles \\
\hline Legend & - & $\mathrm{GB}_{\mathrm{b}}$ & $\mathrm{GB}_{\mathrm{s}}$ \\
\hline Diameter & $\mathrm{mm}$ & 2.5 & 1.5 \\
\hline Density & $\mathrm{kg} / \mathrm{m}^{3}$ & 2524 & 2524 \\
\hline Minimum fluidization velocity & $\mathrm{m} / \mathrm{s}$ & 1.25 & 0.78 \\
\hline Mesh size (x-y-z) & $\mathrm{cm}$ & & \\
\hline
\end{tabular}

Table 1. Simulation parameters.

Table 2. Simulation strategy.

\begin{tabular}{clcccc}
\hline No. & \multicolumn{1}{c}{ Objective } & $\mathbf{U}_{\mathbf{R}}(\mathbf{m} / \mathbf{s})$ & $\mathbf{U}_{\mathbf{H}}(\mathbf{m} / \mathbf{s})$ & $\mathbf{x}_{\mathbf{b}}: \mathbf{x}_{\mathbf{s}} \mathbf{( \% )}$ & Slot size $(\mathbf{m m})$ \\
\hline 1. & Variation of mixture composition & 2.4 & 1.6 & $33: 67,50: 50,67: 33$ & 20 \\
2. & Effect of $U_{\mathrm{R}}$ & $2.4,3.2,4.8,6.4$ & 1.6 & $50: 50$ & 20 \\
3. & Effect of slot size & 2.4 & 1.6 & $50: 50$ & $10,15,20,25,30$ \\
\hline
\end{tabular}


calculations are grid independent, three different mesh schemes (coarse grid size $=0.6 \mathrm{~cm}$, mid grid size $=0.5 \mathrm{~cm}$ and fine grid size $=0.4 \mathrm{~cm}$ ) were examined, resulting in total solid circulation rates of 401,414 and $420 \mathrm{~kg} /$ $\mathrm{m}^{2} \mathrm{~s}$, respectively, where the solid circulation rates of the constituent particles $\mathrm{GB}_{\mathrm{b}} / \mathrm{GB}_{\mathrm{s}}$ are $176 / 225$, $181 / 233,185 / 235$ for the coarse, mid and fine grids. Based on this, the mid grid strategy was chosen in further simulations to ensure calculation accuracy and reduce the computational effort. All simulations were performed for a total time period of $20 \mathrm{~s}$ and timeaveraged values of the desired variables were obtained for the last $15 \mathrm{~s}$ across the slot below the baffle.

\section{SIMULATION RESULTS AND DISCUSSION}

\section{Gas-solid Flow Dynamics}

Figure 2 shows snapshots of the instantaneous solid velocities and bed pressure in the ICFB at $U_{R}=3.2$ and $\mathrm{U}_{\mathrm{H}}=1.6 \mathrm{~m} / \mathrm{s}$. The snapshots reveal the impact of the application of unequal gas velocities to both chambers in the reactor. The high gas holdup in $\mathrm{RC}$ due to high gas velocity $U_{R}$ than the HEC causes a density difference between the chambers in the ICFB. This results in higher pressure in the HEC than the RC, as shown in Figure 2(a). This pressure gradient makes the gas-solid flow possible from the high pressure zone, i.e., the HEC, to the low pressure zone, i.e., RC, through the slot below the baffle. Explosions of the gas bubbles at the bed surface throw the solids from RC to HEC above the baffle. So the separating baffle becomes an important component of this reactor. Contour plots of the solid velocity vectors in the ICFB, Figures 2(b) and (c), clearly show that the solid particles are flowing upward in the $\mathrm{RC}$ and coming down in the HEC. Transfer of particles from the HEC to RC through the slot due to pressure difference between the two chambers can also be seen in the figure. So pressure difference across the slot is the driving force for the solid circulation in the ICFB. Apart from solid

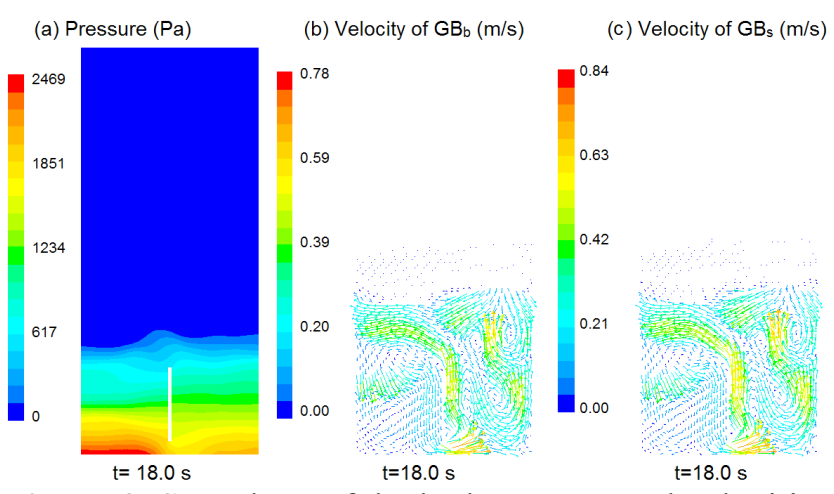

Figure 2. Snapshots of the bed pressure and velocities of the big and small particles in the ICFB. exchange between the two chambers, there is further internal solids circulation within each chamber as well, which will result in good solids mixing and gassolid interaction.

Instantaneous gas pressure calculated near the base of the two chambers in the ICFB is shown in Figure 3(a). It can be seen that the respective gas pressures strongly fluctuate with time. Consistent with Figure 2(a), the gas pressure in HEC is higher than that of the RC. Instantaneous solid circulation rate and gas bypassing flux from the HEC to RC are shown in Figure 3(b). An increase in the gas bypassing flux corresponds to an increase of the solid circulation rate and vice versa. By comparing the circulation rate of the constituent particles of the mixture, the circulation rate of the small particles is higher than that of the big particles under the same pressure drop across the slot. It means that $\mathrm{GB}_{\mathrm{s}}$ particles are easier to be circulated than $\mathrm{GB}_{\mathrm{b}}$ particles. The Granular temperature, which is a measure of the random oscillations of particles, is the basic feature of the kinetic theory of granular flow. It is analogous to the thermal temperature in the kinetic theory of gases. Previous studies (Huilin et al., 2003, Wildman and Parker, 2002, van Sint Annaland et al., 2009 ) on the granular temperature of binary mixtures of particles show that the constituent particles have unequal granular temperatures; this phenomenon is also observed in our case here. Instantaneous granular temperatures of $\mathrm{GB}_{\mathrm{b}}$ and $\mathrm{GB}_{\mathrm{s}}$ particles calculated at the slot in the ICFB are shown in Figure 3(c). The granular temperatures strongly fluctuate with time as the particles are continuously flowing from the HEC to $\mathrm{RC}$ under the influence of the pressure difference across the slot. Both particles have un-equal granular temperatures and fluctuating energy of the $\mathrm{GB}_{\mathrm{b}}$ is larger than that of the $\mathrm{GB}_{\mathrm{s}}$ particles.

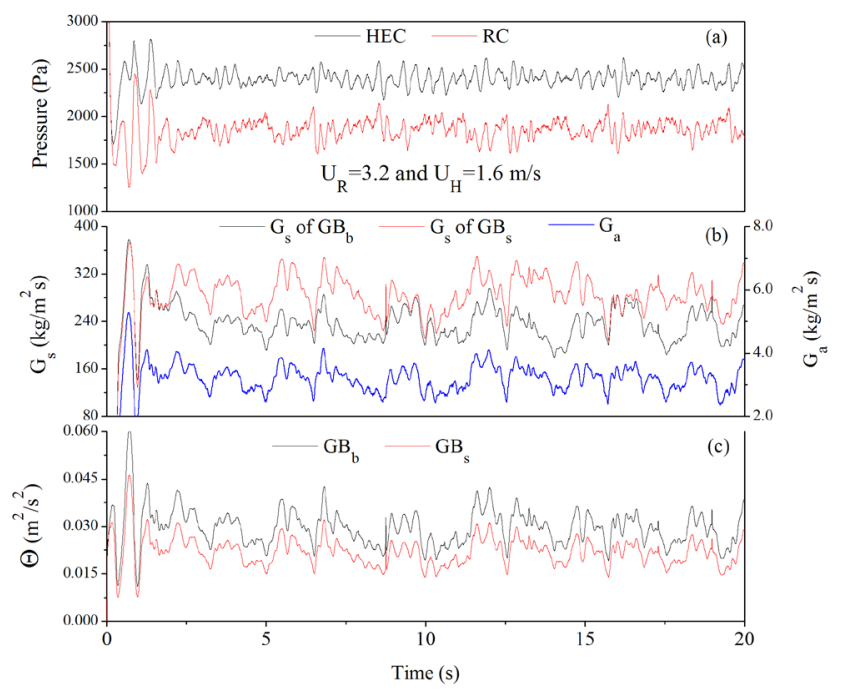

Figure 3. Profiles of the instantaneous gas pressure in the two chambers, solid circulation rate, gas bypassing flux and granular temperatures in the ICFB. 


\section{Effect of Mixture Composition}

This section describes the influence of the variation of the constituent particles concentration on the gassolid flow behavior in the ICFB at $\mathrm{U}_{\mathrm{R}}=2.4$ and $\mathrm{U}_{\mathrm{H}}=$ $1.6 \mathrm{~m} / \mathrm{s}$. The time-averaged solid circulation rate of the binary mixture is plotted in Figure 4(a). It is clear that the mixture composition (x) has a strong impact on the solid circulation rate in the reactor. The particles which make a big portion of the mixture have a high circulation rate and vice versa. Initially, the concentration of the big particles $\mathrm{x}_{\mathrm{b}}$ is lower than that of the small particles $x_{s}$ in the mixture, and consequently the solid circulation rate of $\mathrm{GB}_{\mathrm{s}}$ is higher than for the $\mathrm{GB}_{\mathrm{b}}$ particles. When the smaller particles make up the large portion of the mixture, their circulation rate also becomes higher than for the big particles. But when the constituent particles are equal portions of the mixture $\left(\mathrm{x}_{\mathrm{b}}=\mathrm{x}_{\mathrm{s}}\right)$, then the circulation rate of the smaller particles is higher than for the big particles. Previous studies (Kim et al., 2002, Luo et al., 2013) regarding the effect of particle diameter on the solid circulation rate in single particle system ICFBs show that the circulation rate decreases with increasing particle diameter due to the increasing resistance to the particle flow through the slot. The mixture composition also influences the gas bypassing flux $G_{a}$, Figure 4(b); it increases with the increase of $x_{b}$ in the mixture and the rate of increase also increases due to the high voidage formation as the mixture becomes abundant in big particles. The total mixture circulation rate, as well as the rate of increase of pressure difference across the slot, decreases with increassing $x_{b}$, Figures $4(b)$ and (c).

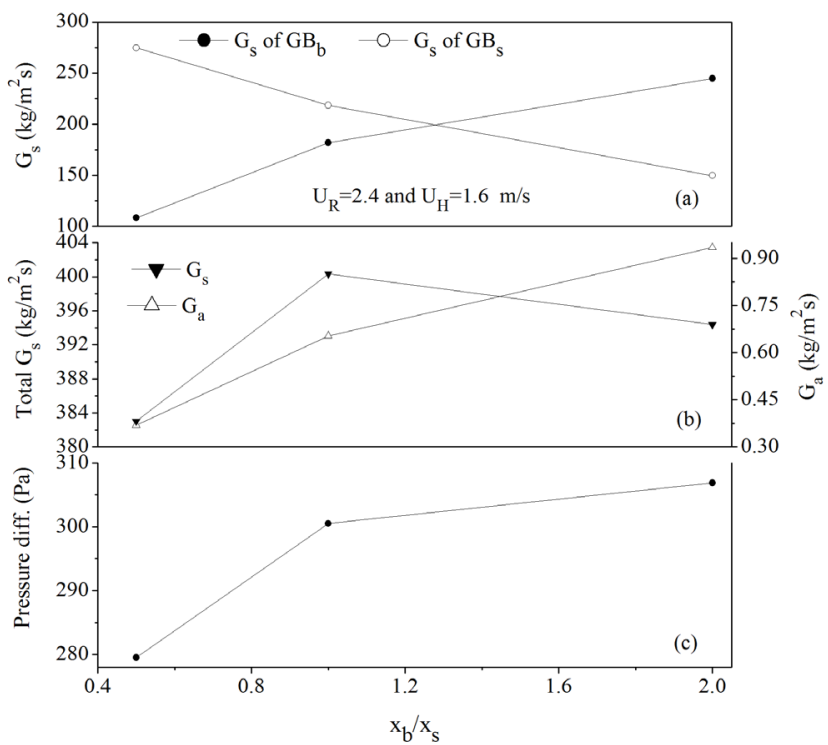

Figure 4. Effect of the variation of concentration of the constituent particles in the mixture on the timeaveraged solid circulation rate, gas bypassing flux and pressure difference between the two chambers in the ICFB.

\section{Effect of the Gas Velocity $U_{R}$}

The fluidization velocity play an important role in controlling the solid cirulation rate and gas bypassing flux in an internally circulating fluidized bed. Figure 5 plots the time-averaged gas pressure in the HEC and $\mathrm{RC}$ of the ICFB as a function of gas velocity ratio. Since bed pressure in fluidized beds has a relation with solids holdup, high gas holdup is developed in RC and comparativlely high solids holdup in the HEC when $\mathrm{U}_{\mathrm{R}}$ is increased at constant $\mathrm{U}_{\mathrm{H}}$. So it can be seen that with the increase of $U_{R}$, the pressure in RC decreased whereas that in the HEC increased. Similar trends were observed in the ICFB with single particles in a previous study (Feng et al., 2012).

The time-averaged solid circulation rate of the mixture through the slot in the ICFB is shown in Figure $6(a)$ as a function of gas velocity ratio. The circulation rate of both particles $\mathrm{GB}_{b}$ and $\mathrm{GB}_{\mathrm{s}}$ increased with increasing $\mathrm{U}_{\mathrm{R}}$. $\mathrm{GB}_{\mathrm{s}}$ particles have a higher circulation rate than the $\mathrm{GB}_{b}$ particles. This is because the big particles are difficult to move through the slot due to the resistance to their flow and this phenomenon was also observed in a previous study (Kim et al., 2002). Figure 6(b) shows the particle transverse timeaveraged velocities through the slot where the GB particles have higher velocity than $\mathrm{GB}_{b}$, explaining the reason behind the differnce of circulation of the two particles. The time-averaged total mixture circulation rate and gas bypassing flux are also shown in Figure 6(c). Both $\mathrm{G}_{\mathrm{s}}$ and $\mathrm{G}_{\mathrm{a}}$ increase with increasing $\mathrm{U}_{\mathrm{R}}$. The pressure difference between the chambers across the slot, which is the driving force behind the circulation rate, is also plotted in Figure 6(d). It can be seen that, with the increase of $U_{R}$, the pressure difference across the gap also increases, consequently leading to an increase in the mixture circulation rate as well as the concurrent gas bypassing flow. The trends are

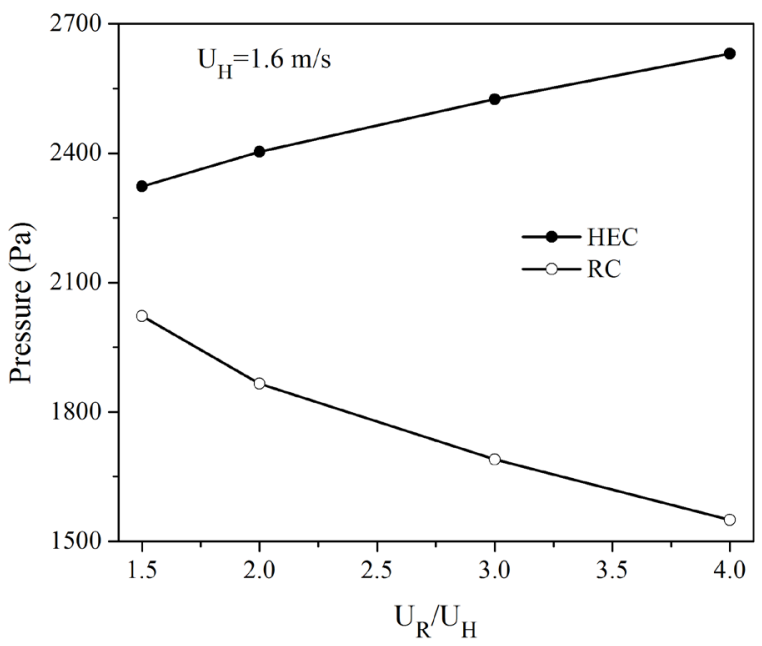

Figure 5. Effect of $U_{R}$ on the time-averaged gas pressure in the two chambers of the ICFB. 


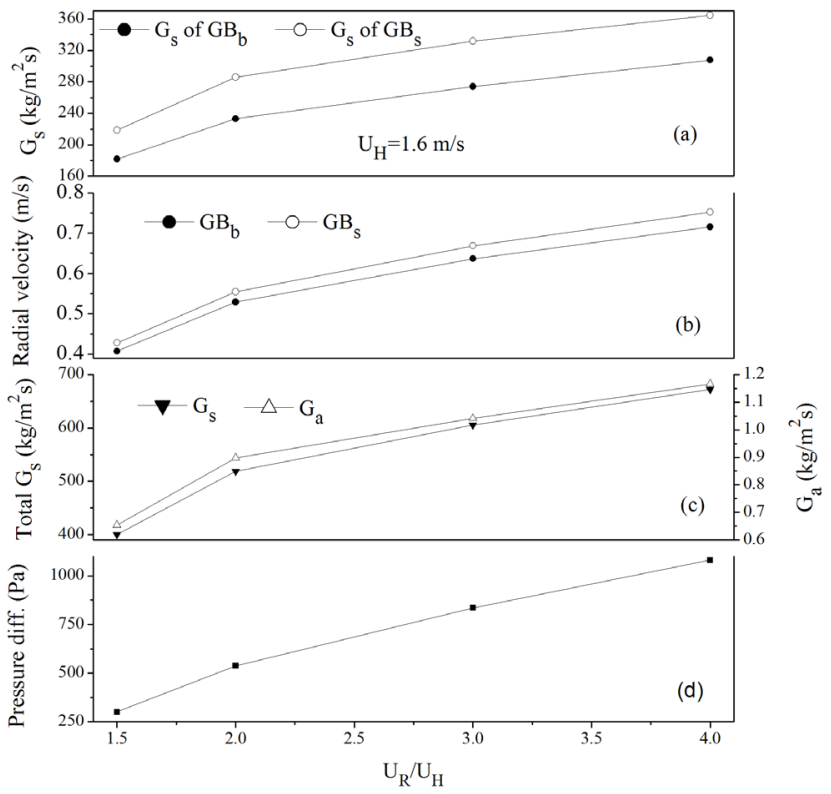

Figure 6. Effect of $U_{R}$ on the time-averaged solid circulation rate, particle velocities, gas bypassing flux and pressure difference between the two chambers of the ICFB.

consistent with the single particle system ICFB (Feng et al., 2012, Luo et al., 2013).

Figure 7 shows the total solid circulation rate of the binary mixture as a function of the pressure difference across the slot between the two chambers. It can be seen that an increase in the pressure difference across the gap between the two chambers corresponds to an increase in the mixture circulation rate and vice versa.

Many studies have been conducted to investigate binary mixtures in bubbling and circulating fluidized beds, but no experimental or numerical study is available regarding mixing and segregation of multisized particles in an ICFB. A brief description of mixing

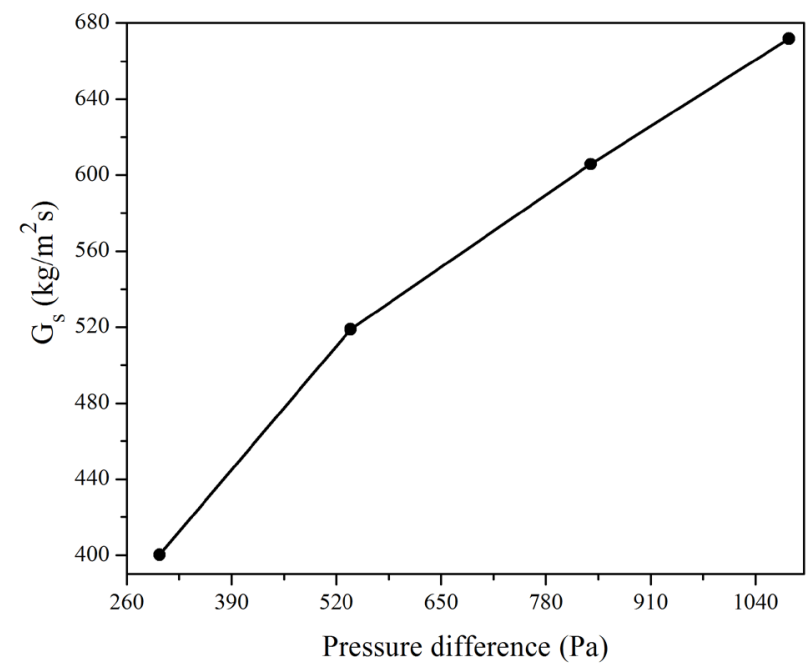

Figure 7. Profile of the total solid circulation rate as a function of the pressure difference between the HEC and $\mathrm{RC}$. and segregation has been shown in Figure 8 in the ICFB only at $U_{R}=3.2$ and $U_{H}=1.6 \mathrm{~m} / \mathrm{s}$ in terms of $\mathrm{GB}_{b}$ volume fraction. It can be seen that obvious segregation has occurred at the top and bottom regions in the ICFB but in the middle region segregation is comparatively reduced. However, detailed investigations (beyond such a proof-of-concept study) are required and currently underway to study the influence of chamber gas velocities, mixture composition and slot size etc., on mixing and segregation of multi-sized particles in an internally circulating fluidized bed.

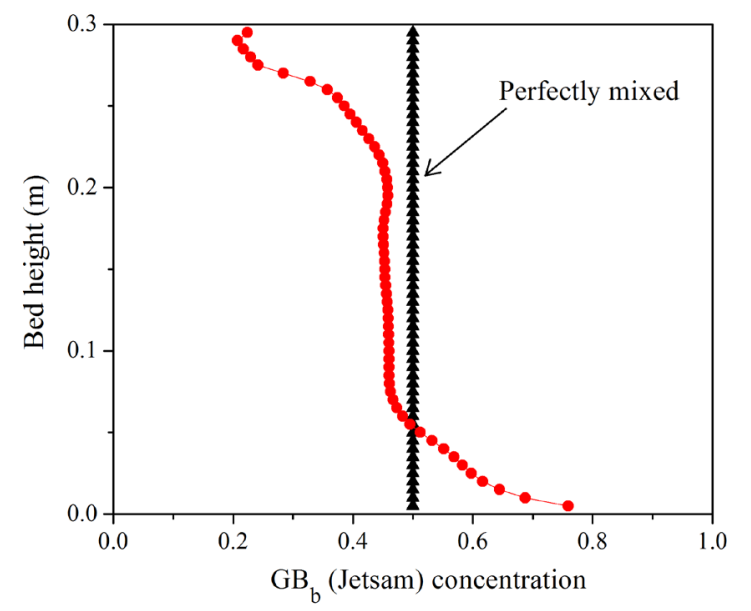

Figure 8. Time-averaged volume fraction of $\mathrm{GB}_{\mathrm{b}}$ particles in the ICFB.

\section{Effect of Slot Size}

As with the fluidization velocity, the slot size is also very important to control the solid circulation rate in the ICFB. Figures 9(a), (b) and (c) show that,

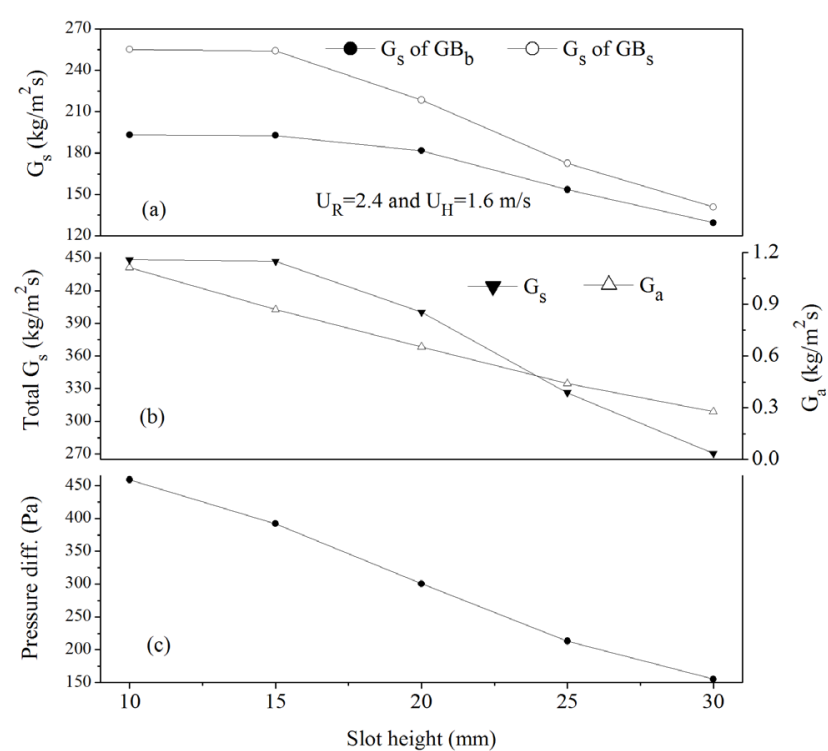

Figure 9. Effect of the variation of slot size on the time-averaged solid circulation rate, gas bypassing flux and pressure difference between the two chambers in the ICFB. 
at given gas velocities $\mathrm{U}_{\mathrm{R}}$ and $\mathrm{U}_{\mathrm{H}}$, an increase in the slot size results in a decrease of the time-averaged $G_{s}$ and $\mathrm{G}_{\mathrm{a}}$. This is caused by the corresponding decrease in the pressure difference across the slot between the chambers, which is the main driving force behind $\mathrm{G}_{\mathrm{s}}$ and $\mathrm{G}_{\mathrm{a}}$. The rate of decrease of $\mathrm{G}_{\mathrm{s}}$ of the $\mathrm{GB}_{\mathrm{s}}$ particles is higher than that of the $\mathrm{GB}_{\mathrm{b}}$ particles, which means that the big particles can pass with more ease when the slot area is increased.

\section{CONCLUSIONS}

Fluidized bed systems usually operate with complex bed materials of different properties, size and density. CFD simulations are performed to study the gas-solid flow dynamics in an ICFB having a binary mixture, using the multi-fluid EulerianEulerian approach incorporating the kinetic theory of granular flow using ANSYS-Fluent. The binary mixture is composed of two particles having different sizes but the same density. The influence of several design and operating parameters such as superficial gas velocity, variation in concentration of the constituent particles and slot size is investigated and the results were quantified in terms of the solid circulation rate $\left(\mathrm{G}_{\mathrm{s}}\right)$.

The investigated parameters had a significant impact on the performance of the ICFB. The gas flow deviation along with the rise, coalescence and eruption of bubbles in the reaction chamber (RC) is responsible for the solids circulation from the $\mathrm{RC}$ to the HEC above the baffle. The pressure difference between the two chambers (developed due to unequal aeration) is responsible for the solids recirculation through the slot under the baffle from the HEC to the $\mathrm{RC}$. The circulation rate of the small particles $\mathrm{GB}_{\mathrm{s}}$ was found to be higher than that of the big particles $\mathrm{GB}_{b}$ and both particles have unequal granular temperatures. The gas velocity $U_{R}$ strongly influences the solid circulation rate and pressure drop across the slot. An increase in the RC gas velocity $U_{R}$ at constant HEC velocity $U_{H}$ results in an increase in the circulation rate of the binary mixture. Increase in the slot size causes a decrease in the pressure difference between the chambers, ultimately decreasing the $G_{s}$ and $G_{\text {in }}$ in the ICFB. The predicted results show that the CFD model applied has the ability to capture the complex hydrodynamics in the ICFB.

\section{ACKNOWLEDGEMENT}

This work is supported by the Natural Science Foundation of China through grant No. 51421063 and No. 11472093.

\section{NOMENCLATURE}

$\begin{array}{ll}C_{D} & \text { Drag coefficient } \\ d & \text { Diameter }(\mu \mathrm{m}) \\ e & \text { Restitution coefficient } \\ g & \text { Gravity }\left(\mathrm{m} / \mathrm{s}^{2}\right) \\ g_{o} & \text { Radial distribution function } \\ k_{\Theta} & \text { Diffusion coefficient for granular energy } \\ & (\mathrm{kg} / \mathrm{ms}) \\ \bar{I} & \text { Unit tensor } \\ I_{2 D} & \text { Second invariant of deviatoric stress tensor } \\ p & \text { Pressure }(\mathrm{Pa}) \\ \mathrm{u} & \text { Velocity vector }(\mathrm{m} / \mathrm{s}) \\ R e & \text { Reynolds number } \\ t & \text { Time }(\mathrm{s}) \\ \Theta & \text { Granular temperature }\left(\mathrm{m}^{2} / \mathrm{s}^{2}\right) \\ \varnothing & \text { Internal friction angle }\left({ }^{\circ}\right) \\ \mathrm{X} & \text { Particle concentration } \\ \text { CFD } & \text { Computational fluid dynamics }\end{array}$

Greek letters

$\alpha \quad$ Volume fraction

$\rho \quad$ Density $(\mathrm{kg} / \mathrm{m})$

$\tau \quad$ Stress tensor $(\mathrm{Pa})$

$\beta \quad$ Inter-phase momentum exchange coefficient $\left(\mathrm{kg} / \mathrm{m}^{3} \mathrm{~s}\right)$

$\gamma \quad$ Collisional energy dissipation $\left(\mathrm{kg} / \mathrm{ms}^{3}\right)$

$\lambda \quad$ Bulk viscosity $(\mathrm{kg} / \mathrm{ms})$

$\mu \quad$ Shear viscosity $(\mathrm{kg} / \mathrm{ms})$

$\alpha_{\mathrm{s}, \max } \quad$ Maximum solid volume fraction

\section{Subscripts \\ a Gas phase \\ $i, j \quad$ Solid phases}

\section{REFERENCES}

Bai, W., Keller, N. K. G., Heindel, T. J. \& Fox, R. O., Numerical study of mixing and segregation in a biomass fluidized bed. Powder Technology, 237, 355-366 (2013).

Boyd, T., Grace, J., Lim, C. J. \& Adris, A. E. M., Hydrogen from an internally circulating fluidized bed membrane reactor. International Journal of Chemical Reactor Engineering, 3(1), 81-83 (2005).

Chu, C. Y. \& Hwang, S. J., Flue gas desulfurization in an internally circulating fluidized bed reactor. Powder Technology, 154, 14-23 (2005).

Fang, M. M., Luo, K., Yang, S. L., Zhang, K. \& Fan, J. R., LES-DEM investigation of gas-solid flow dynamics in an internally circulating fluidized bed. Chemical Engineering Science, 101, 213-227 (2013).

Fedors, R. F. \& Landel, R. F., An Empirical method of estimating the void fraction in mixtures of uniform particles of different size. Powder Technology, 23, 225-231 (1979). 
Feng, Y. Q., Swenser-Smith, T., Witt, P. J., Doblin, C., Lim, S. \& Schwarz, M. P., CFD modeling of gassolid flow in an internally circulating fluidized bed. Powder Technology, 219, 78-85 (2012).

Fluent, A., 14.5 Theory Guide. Canonsburg, PA, USA: ANSYS Inc, (2012).

Foscolo, P. U., Germanà, A., Jand, N. \& Rapagnà, S., Design and cold model testing of a biomass gasifier consisting of two interconnected fluidized beds. Powder Technology, 173, 179-188 (2007).

Gera, D., Syamlal, M. \& O’brien, T. J., Hydrodynamics of particle segregation in fluidized beds. International Journal of Multiphase Flow, 30, 419428 (2004).

Gidaspow, D. 1994. Multiphase Flow and Fluidization: Continuum and Kinetic Theory Descriptions, Academic Press.

Gidaspow, D., Bezburuah, R. \& Ding, J. 1991. Hydrodynamics of circulating fluidized beds: kinetic theory approach. Illinois Inst. of Tech., Chicago, IL (United States). Dept. of Chemical Engineering.

Goldschmidt, M. J. V., Kuipers, J. A. M. \& Swaaij, W. P. M., Segregation in dense gas-fluidised beds: validation of a multi-fluid continuum model with non-intrusive digital image analysis measurements. In: Fluidization $X$. Engineering Foundation Conference on Fluidization. 795-802 (2001).

Hassan, M., Schwarz, M. P., Rafique, M., Feng, Y., Liu, G., Witt, P. J., Wang, S. \& Lu, H., Numerical Simulations of Solid Circulation Characteristics in an Internally Circulating Elevated Fluidized Bed. Chemical Engineering \& Technology, 40, 769-777 (2017).

Hassan, M., Schwarz, M. P., Yuqing, F., Rafique, M., Witt, P. \& Huilin, L., Numerical investigation of solid circulation flux in an internally circulating fluidized bed with different gas distributor designs. Powder Technology, 301, 1103-1111 (2016).

Huilin, L. \& Gidaspow, D., Hydrodynamics of binary fluidization in a riser: CFD simulation using two granular temperatures. Chemical Engineering Science, 58, 3777-3792 (2003).

Huilin, L., Yurong, H. \& Gidaspow, D., Hydrodynamic modelling of binary mixture in a gas bubbling fluidized bed using the kinetic theory of granular flow. Chemical Engineering Science, 58, 11971205 (2003).

Jeon, J. H. \& Kim, S. D., Hydrodynamic Characteristics of Binary Solids Mixtures in a Square Internally Circulating Fluidized Bed. Journal of Chemical Engineering of Japan, 43, 126-131 (2010).

Johnson, P. C. \& Jackson, R., Frictional-collisional constitutive relations for granular materials, with application to plane shearing. Journal of Fluid Mechanics, 176, 67-93 (1987).
Kim, S. D., Kim, Y. H., Roh, S. A. \& Lee, D. H., Solid circulation characteristics in an internally circulating fluidized bed with orifice-type draft tube. Korean Journal of Chemical Engineering, 19, 911-916 (2002).

Kim, Y. J., Lee, J. M. \& Kim, S. D., Coal gasification characteristics in an internally circulating fluidized bed with draught tube. Fuel, 76, 1067-1073 (1997).

Lee, J. M., Kim, Y. J. \& Kim, S. D., Catalytic coal gasification in an internally circulating fluidized bed reactor with draft tube. Applied Thermal Engineering, 18, 1013-1024 (1998).

Li, P. L., Yu, X. Y., Liu, F. \& Wang, T. F., Hydrodynamic behaviors of an internally circulating fluidized bed with wide-size-distribution particles for preparing polysilicon granules. Powder Technology, 281, 112-120 (2015).

Loha, C., Chattopadhyay, H. \& Chatterjee, P. K., Assessment of drag models in simulating bubbling fluidized bed hydrodynamics. Chemical Engineering Science, 75, 400-407 (2012).

Lun, C. K. K., Savage, S. B., Jeffrey, D. J. \& Chepurniy, N., Kinetic theories for granular flow: inelastic particles in Couette flow and slightly inelastic particles in a general flowfield. Journal of Fluid Mechanics, 140, 223-256 (1984).

Luo, K., Fang, M. M., Yang, S. L., Zhang, K. \& Fan, J. R., LES-DEM investigation of an internally circulating fluidized bed: Effects of gas and solid properties. Chemical Engineering Journal, 228, 583-595 (2013).

Manual, F., ANSYS/FLUENT Release Version 14.5. ANSYS Inc., Documentation, (2012).

Milne, B. J., Behie, L. A. \& Berruti, F., Recycling of waste plastics by ultrapyrolysis using an internally circulating fluidized bed reactor. Journal of Analytical and Applied Pyrolysis, 51, 157-166 (1999).

Mukadi, L., Guy, C. \& Legros, R., Modeling of an Internally Circulating Fluidized Bed reactor for thermal treatment of industrial solid wastes. Canadian Journal of Chemical Engineering, 77, 420-431 (1999a).

Mukadi, L., Guy, C. \& Legros, R., Parameter analysis and scale-up considerations for thermal treatment of industrial waste in an internally circulating fluidized bed reactor. Chemical Engineering Science, 54, 3071-3078 (1999b).

Schaeffer, D. G., Instability in the Evolution-Equations Describing Incompressible Antigranulocytes Flow. Journal of Differential Equations, 66, 19-50 (1987).

Syamlal, M., Rogers, W. \& O'brien, T. J., MFIX documentation: Theory guide. National Energy Technology Laboratory, Department of Energy, Technical Note DOE/METC-95/1013 and NTIS/ DE95000031, (1993). 
Taghipour, F., Ellis, N. \& Wong, C., Experimental and computational study of gas-solid fluidized bed hydrodynamics. Chemical Engineering Science, 60, 6857-6867 (2005).

Van Sint Annaland, M., Bokkers, G. A., Goldschmidt, M. J. V., Olaofe, O. O., Van Der Hoef, M. A. \& Kuipers, J. A. M., Development of a multi-fluid model for poly-disperse dense gas-solid fluidised beds, Part II: Segregation in binary particle mixtures. Chemical Engineering Science, 64, 4237-4246 (2009).

Wildman, R. \& Parker, D., Coexistence of two granular temperatures in binary vibrofluidized beds. Physical Review Letters, 88, 064301 (2002).
Xiao, X. B., Le, D. D., Morishita, K., Zhang, S. Y., Li, L. Y. \& Takarada, T., Multi-stage biomass gasification in Internally Circulating Fluidized-bed Gasifier (ICFG): Test operation of animal-wastederived biomass and parametric investigation at low temperature. Fuel Processing Technology, 91, 895-902 (2010).

Zhong, H., Gao, J., Xu, C. \& Lan, X., CFD modeling the hydrodynamics of binary particle mixtures in bubbling fluidized beds: Effect of wall boundary condition. Powder Technology, 230, 232-240 (2012). 